\title{
On Phrasal and Prepositional Verb Projections in Turkish
}

\author{
Murat Özgen, Özgün Koşaner \\ Department of Linguistics, Dokuz Eylül University, İzmir, Turkey \\ Email: murat.ozgen@deu.edu.tr, ozgun.kosaner@deu.edu.tr
}

Received 4 November 2015; accepted 6 December 2015; published 9 December 2015

Copyright (C) 2015 by authors and Scientific Research Publishing Inc.

This work is licensed under the Creative Commons Attribution International License (CC BY). http://creativecommons.org/licenses/by/4.0/

cC) (i) Open Access

\begin{abstract}
Radford (1988: p. 101) differentiated between the phrasal verbs and prepositional verbs on both conceptual and empirical grounds. He suggested eight different tests with respect to their empirical dimensions. The aim of the study is to seek an answer to the question as to whether there is a distinction between these two kinds of verbs within the framework of the tests of Radford (1988) which are applicable to Turkish data (e.g. scrambling, sentence fragment and adverb placement) and the tests we have suggested (preposition alteration, cleft structures and synonymy). The subsidiary aim of the study is to observe the theoretical implications of such a distinction with respect to the discussions over the question as to whether PPs do really constitute a phase in the sense of Chomsky (2001 \& subsequent studies). As for the first question, the first intuitional observations show that there is a distinction between such verb phrases as "karşı çı-" (lit. to stand against), and "karşısına çık-" (lit. to stand in front of sb.) on semantic grounds. The empirical tests also show that phrasal verbs do exist in Turkish unlike the common view in literature, and that they behave in a different manner than prepositional verbs. Depending on the above-stated empirical tests and intuitive judgments, this distinction may also provide insights as to the phasehood of PPs in that the agreeing PPs in Turkish can constitute phases while the bare PPs cannot.
\end{abstract}

\section{Keywords}

Phase, Agreeing PP, Bare PP, Phrasal Verb, Prepositional Verb

\section{Introduction}

As Chomsky (2001, 2004, \& 2008) puts it, C and $v$ are argued to be the phase heads. T is not defined as a phase head in his discussions:

1) [+ phase]: C, $v(*)$ 
2) [- phase]: T

All those heads are also defined as Core Functional Categories (CFCs). They may bear uninterpretable $\varphi$-features; however, only $\mathrm{C}$ can be unselected (i.e. be the root). $\mathrm{T}$ is defective if and only if it is not selected by C (Chomsky, 2001: p. 102). In other words, $T$ has a full set of $\varphi$-features if selected by C. The chunk of deriva-

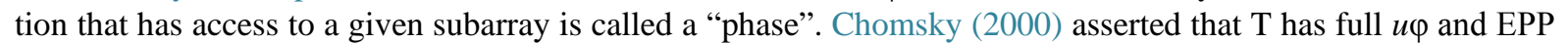
(Extended Projection Principle) features. $\mathrm{T}_{\text {def }}$ means the lack of one of those features. In that case, $\mathrm{T}$ cannot delete all the features of a goal.

It assumed in the literature that PPs also constitute phases (see Abels, 2003; Drummond, Hornstein, \& Lasnik, 2010). This means that they have escape hatches through which they allow movement of phase-internal syntactic items. Şener (2006) states that in Turkish there are two versions of PPs (postpositional phrases): the agreeing PPs vs. bare PPs. The former refers to a PP in Turkish which has a richer morphological structure and allows extraction of the complements of agreeing PPs without inducing an Antilocality Condition (ALC), which basically states that no phrase can be both the complement and the specifier to the same head (Abels, 2003):

3) Murat dün $\quad \operatorname{spp}_{\mathrm{i}}$ inc-in- $t_{\mathrm{i}}$ ing $]$ bağır-dı. Murat-nom class-gen yesterday in-3sg.agr-loc shout-past

"Murat shouted in the class yesterday."

As put forward by Şener (2006: p. 3), if agreeing PPs are identical/similar to bare PPs in their basic structure, then movement of the genitive complement stranding P should result in an ALC violation, contrary to fact. As seen in (4), bare PPs do not allow such a stranding:

4) *Murat öğrenci-ler ${ }_{\mathrm{i}}$ dün [pp $t_{\mathrm{i}}$ için] hediye-ler al-dı. Murat-nom student-pl yesterday for present-pl buy-past

"Murat bought presents for the students yesterday."

Besides Şener (2006), Göksel \& Kerslake (2005: p. 114) make the same distinction as well. They call the first type bare postpositions, while the second is named as possessive marked postpositions. Kornfilt (1997) follows Lewis (1975) and names such postpositions respectively as bare postpositions and secondary postpositions. Depending on this distinction between the agreeing-PPs and bare-PPs in literature on Turkish, we assume that this distinction is also reflected onto the co-occurrence of such agreeing or bare PPs with the verbs. The first intuitional observations show that there is a distinction between such verb phrases as "karşı çık-" (lit. to stand against), and "karşısına çık-" (lit. to stand in front of sb.) on semantic grounds:

5) Can baba-sı-nın karşı-sı-na çık-tı

Can father-poss-genagainst-poss-dat stand-past

"John (suddenly) stood in front of his father his father"

6) Can baba-sı-na karşı çık-tı

Can father-poss-dat against stand-past

"John stood against his father."

(5) basically states a spatial action in which the agent of the verb "Can" suddenly shows up in front of the goal of the verb "pro babası". However, in (6) displays a different argument relationship in that the agent of the verb "Can" contradicts the goal of the verb "pro babass" in terms of opinions, thoughts etc.

We maintain the idea that both prepositional verbs and phrasal verbs do exist in Turkish as well. We will try to show that this distinction is also borne out with the empirical tests of Radford (1988) applicable to Turkish data (e.g. scrambling, sentence fragment and adverb placement) and the tests we have suggested (e.g. preposition alteration, cleft structures and synonymy). Then, we will move on to discuss its theoretical implications about the question as to whether PPs do really constitute phases, as we assume that the prepositional verbs include agreeing PPs, whereas phrasal verbs include the bare postpositions.

The study is organized as follows: In Section 2, we summarize the distinction between a prepositional verb and a phrasal verb. In Section 3, we touch upon the tests Radford (1988) suggested and apply them onto Turkish data. In Section 4, we discuss the theoretical implications of such a distinction as to the phasehood of PPs. In Section 5, we conclude the study.

\section{Prepositional verb vs. phrasal verb}

Let us have a look at the two sentences below taken from Radford (1988: p. 90):

7) a. Drunks would get off the bus. 
b. Drunks would put off the customers.

The first intuition about these two sentences is that they have a similar structure. This is due to the fact that they are both comprised of the lexical items out of the same lexical categories. If we parse them, we see that there is a noun (Drunks), a modality marker (would), a verb (get), a preposition (off), a determiner (the) and another noun (bus/customers). However, if we closely inspect these two sentences, two different structures come out beneath the sentences.

In (7a), the preposition [off] merges with the Determiner Phrase [the bus] to form a Prepositional Phrase [off the bus]:

8) a. Drunks would get [pp off the bus].

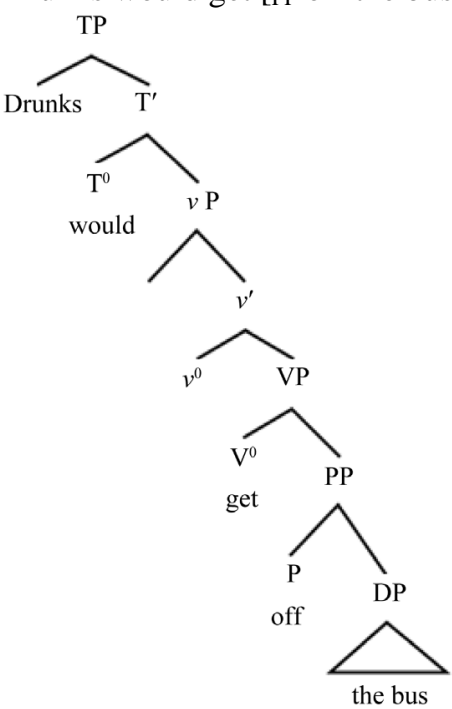

b. the bus

As seen in the tree diagram (8b), the Verb merged with a PP to from a Verb Phrase. To talk in traditional terms, the Verb get is a prepositional verb due to the fact that it is a verb which takes a PP complement, as stated by Radford (1988: p. 91).

On the other hand, if we closely inspect (7b), we see that it is another of type of traditionally named verb group, namely, phrasal verb:

9) a. Drunks would [vp put off] the customers

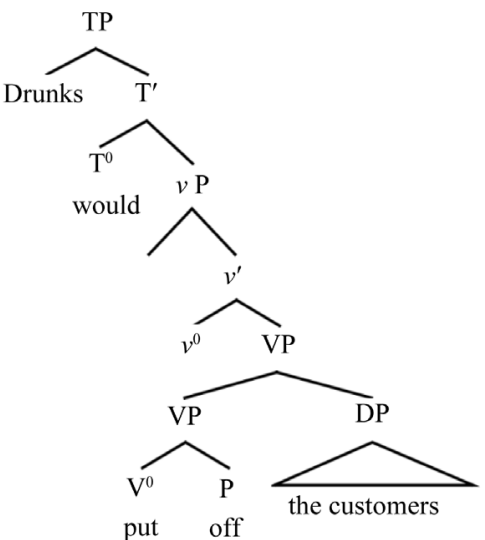

As seen in (9b), the Verb put and the Preposition merges to form a VP layer [put off]. They two seem to form a special type of compound verb. Next, we will discuss the empirical evidences of the distinction within the framework of the tests suggested by Radford (1988), and the tests we suggested with respect to the original discussions of Radford (1988) and Turkish data.

\section{Empirical Grounds}

Radford (1988) suggested various tests to highlight the distinction empirically. We will not go into details of 
each test, but discuss those which are applicable to Turkish data. In addition, we will also have a look at some other tests that prove the empirical grounds of such a distinction between prepositional and phrasal verbs in Turkish.

\subsection{Movement}

The first test we will apply to Turkish data comes from movement data. What he suggests is that only full phrases can undergo movement; therefore, he notes that in get off structures like (10) the whole PP can be scrambled to a sentence initial position to derive emphasis:

10) Every afternoon, the big red bus would stop in front of the village clock, and [pp off the bus] would get a dear old lady carrying a shopping bag.

(Radford, 1988: p. 95)

As he maintains the fact that only full phrases can undergo movement, it is observed that the italicized PP in (10) must be a full phrases headed by a P [off]; thus, a PP. This clearly shows that the verb in (10) is a prepositional phrase which merges with $\mathrm{V}$ to form a prepositional phrase. In contrast to what we have observed in (10), PP in (11) cannot be preposed:

11) *The manager suspects that drunks would put off the customers, and [off the customers] they certainly would put.

(Radford, 1988: p. 95)

Remember the tree diagram in (9). It is clearly seen that $\mathrm{P}$ and $\mathrm{V}$ merge to form a VP meaning that only this partial VP can be moved to sentence initial position. This argument is borne out by (12):

12) The manager suspects that drunks would put off the customers, and [put off the customers $]_{i}$ they certainly would $t_{i}$.

The answer to the question as to why it should be the case is that only full phrases can be preposed in the relevant data. We can infer from the data in (11) that [off the customers] isn't a full phrase. This shows that only P is merged with $\mathrm{V}$ to form a phrasal verb (see the diagram in 9).

Now, if we apply the same scrambling test to Turkish data, we derive the same conclusions:

13) a. Oyuncu [vp [pp savunma hattı-nın geri-si-nde] kal]dı

$$
\text { player defensive line-gen back-poss-loc stay-past }
$$

b. [pp Savunma hattı-nın geri-si-nde $]_{\mathrm{i}}$ oyuncu [vp $t_{\mathrm{i}} \mathrm{kal}$ ]d $\mathrm{d}$

c. [geri-si-nde $]_{\mathrm{i}}$ oyuncu [vp [pp savunma hattı-nın $t_{\mathrm{i}}$ ] kal] dı

"The player stayed back of the defensive line."

If we assume the [savunma hattl-nin geri-si-nde] as a PP, we see that as a PP, it is allowed to move out of the VP it is embedded. This shows that the verb in (13) is a prepositional verb. Compare this data with the following data in (14):

14) a. Oyuncu antrenman-lar-dan [vp geri kal]d1

player training-pl-loc back stay-past

b. *Geri $\mathrm{k}_{\mathrm{k}}$ oyuncu antrenmanlardan [vp $\left.t_{\mathrm{k}} \mathrm{kal}\right] \mathrm{d} \mathrm{l}$

"The player fell behind the training schedule."

The contrast between (13) and (14) suggests that in (14) P [geri] merged with verb to form a VP, out of which an extraction is disallowed as seen in (14b). The ungrammaticality of (14b) reveals that the verbal sequence geri kal-is a phrasal verb.

\subsection{Sentence Fragment}

What Radford meant by sentence fragment test is that some full phrases of the sentence can be used as an answer to a specific question:

15) A: Who will eat the cheesecake?

B: [DP The children]

In (15), assuming that the questioned part is the subject of the sentence, the answer only includes the questioned part (i.e. [DP The children]). This shows that the fragmented part of the full answer such as "[Dp The children] will eat the cheesecake" is enough for the grammaticality. What is interesting here is that only full phrases are allowed to be used as sentence fragments:

16) A: Who will eat the cheesecake? 


\section{B: *The}

On this ground, if we apply this test to prepositional verbs and phrasal verbs in English, we will see that the structure of these two types of verbal groups is different from each other, as observed in Radford (1988: p. 96):

17) A: Did he get off the train?

B: No, off the bus.

18) A: Would drunks put off the waitresses?

$\mathrm{B}: *$ No, off the customers.

The contrast between (17) and (18) suggests that the sentence fragment test yields the same results, for the italicized sequence can serve as sentence fragment while the sequence in (18) cannot. The answer to the question as to why the sequence in (18) cannot be a sentence fragment is that it is not even a constituent let alone a full phrase. Remember that only full phrases of the sentence can be used as sentence fragments.

Depending on this contrast between (17) and (18) and the basic mechanism of the sentence fragment test, the distinction seems to be viable in Turkish as well:

19) A: Oyuncu [vp [pp savunma hattı-nın geri-si-nde $]$ mi kal]di? player defensive line-gen back-poss-loc Q stay-past

B: Hayır, ileri-si-nde / Hayır, hücum hattı-nın geri-si-nde no ahead-poss-loc no offensive line-gen back-poss-loc

"A: Did the player stay back of the defensive line?

B: (lit.) No, ahead / No, back of the offensive line”

(19) makes the details clear in a way that what is assumed as a prepositional verb composed of a V merged with a PP allows the constituent PP to be used as a sentence fragment. Therefore, we see that in the answer of B the fragments ilerisinde or hücum hattının gerisinde are grammatical, as they are assumed to be PPs. Compare this with (20):

20) A: Oyuncu antrenman-lar-dan [vp geri mi kal]dı?

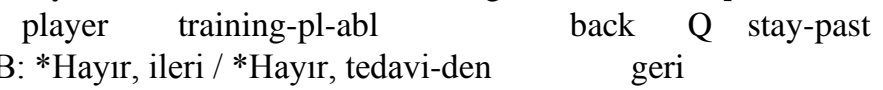

no ahead no treatment-abl back

"A: Did the player fall behind the training schedule?

B: (lit.) No, ahead / No, behind the treatment”

Unlike (19), (20) does not have a prepositional verb composed of a V merged with PP, but a VP composed of V merged with a P head. Given that only full phrases are allowed as sentence fragments, we may infer from (20) that there is no full PP in the relevant data but a VP${ }^{1}$. Therefore, the distinction is again proved empirically as observed by movement test.

\subsection{Adverb Placement}

If we follow Cinque (1999) and assume that some adverbials are low in that they are attached to VP while others are high in that they are attached to either TP or CP level, we may use VP-level adverbials to differentiate between prepositional and phrasal verbs, since phrasal verbs consist of a V and P merged together. Radford (1988) calls the first type of adverbials as VP-adverbials, and the second S-adverbials (sentence adverbials). The class of VP-adverbial type includes adverbials such as quickly, slowly, completely etc. Bearing such adverbials in mind, these types of adverbs can be positioned between $\mathrm{V}$ and PP in prepositional verbs and below, this intuition is borne out:

21) a. Drunks would get slowly off the bus.

b. [TP Drunks would [ ${ }_{v \mathrm{P}} v^{0}+$ get [VP slowly [VP $<$ get $>$ [PP off the bus]]]]]

Assuming that $\mathrm{V}_{\text {[get] }}$ is raised to adjoin $v^{0}$, we see that the italicized ADV adjoins VP. By contrast, there is no position for the ADV to adjoin within the joint segment VP in phrasal verbs:

22) a. *Drunks would put completely off the customers.

b. ${ }^{*}{ }_{\mathrm{TP}}$ Drunks would ${ }_{{ }_{\nu \mathrm{P}}} v^{0}+$ put [ ${ }_{\mathrm{VP}}$ completely $\left[{ }_{\mathrm{V}},<\right.$ put $>$ off [DP the customers] $\left.\left.]\right]\right]$

${ }^{1}$ This means that when we use VP as sentence fragment, it seems grammatical:

(1) A: Oyuncu [vp antrenmanlardan geri mi kald1]?

B: Hayır , [vp tedaviden geri kaldi]

"A: Did the player fall behind the training schedule

B: No, he stayed behind the treatment." 
As seen, VP in (22b) is a joint segment; thus, a movement due to a feature checking should pied-pipe the preposition as well. What is more is that, the ADV in (22b) is not adjoined to VP but merged with V' level, which is contradictory with their status as low adverbials. This test also predicts the status of prepositional verbs vs. phrasal verbs.

Returning to Turkish data, we see that the same test also holds:
23) Ali baba-s1-nın
karş1-s1-na
saygısızca çı-tı.
Ali father-poss-gen against-poss-dat disrespectfully stand-past

"Ali stood against his father in a disrespectful way."

If we analyze the sentence in (23a), we observe that VP-internal adverbial sayglsizca is allowed to intervene between $\mathrm{V}$ and PP: $\left.\mathrm{T}^{0}\right]$ ]

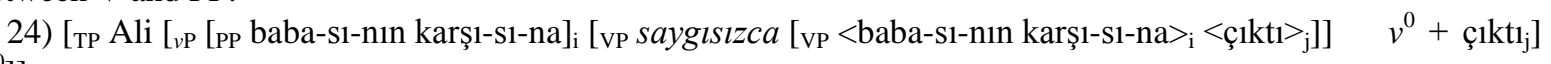

Following Öztürk (2005), we assume that the indirect objects are raised to remerge at [Spec, vP] to be licensed $^{2}$ for case and role checking; therefore, the VP-level adverbial saygisizca can adjoin. By contrast, there is no position again for the ADV in phrasal verb projections in Turkish as has been observed in English data (see $(22 a-b))$ :

25) a. *Ali baba-sı-na karşı saygısızcaçık-tı.

Ali father-poss-dat against disrespectfully stand-past

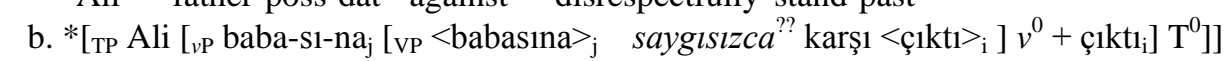

As can be observed from (25b), no position is available within VP as it is already composed of three lexical items two of which are obligatory arguments of the verb. Due to the fact that the ternary branching is not allowed in modern studies, VP-internal adverbial saygisizca cannot adjoin within VP; thus, the ungrammaticality of (25).

The third test also proves the empirical difference between the prepositional and phrasal verbs just as the former empirical tests display the difference between them.

\subsection{Postposition Alternation}

Apart from the tests suggested by Radford (1988), we now move onto the tests we have suggested in order to display the empirical difference between these two kinds of verb types.

The first evidence that these two kinds of verb types do exist in Turkish comes from a test we name as postposition alternation. What lies behind this test is that the spatial conceptualization of the PP still exists in prepositional verb types (see (5)), while there is the spatial conceptualization of the $\mathrm{P}$ is eliminated in $\mathrm{V}+\mathrm{P}$ constructions. Therefore, one may expect to alternate the postposition in the so-called prepositional constructions, which is indeed the case:

26) Oyuncu savunma hattının gerisinde/ilerisinde/sağında/solunda kaldı

"The player stayed back/forward/at the right/left of the defensive line"

As has already been discussed, the prepositional verbs are composed of a V merged with PP; thus, we may alternate the P head within PP since it conceptualizes a spatial relation with the verb. On the other hand, no alternation of postposition is allowed in phrasal verb construction:

27) Oyuncu antrenmanlardan geri/*ileri/*ön/*arka kaldı.

"The player fell behind/(lit.)further/front/back the training schedule."

We have seen that the postpositions can be alternated in the so-called prepositional verb constructions while it is impossible to alternate the Ps in phrasal verb constructions. This also proves the empirical difference between these two types of constructions.

\subsection{Cleft Constructions}

A cleft sentence is a complex sentence composed of a relative clause and a main clauase containing a copula “-(I)mEk, -DIr" or " Ø” in Turkish (Turan, 2002: 59). Consider in English that there are two kinds of cleft constructions: it-clefts vs. wh-clefts (i.e. pseudo-clefts):

\footnotetext{
${ }^{2}$ In the original account of Öztürk (2005), such role projections as CauseP, AgentP, ThemeP are used to distinguish the different layers within $v \mathrm{P}$ to mark the difference between the theta roles of the arguments of a verb. We adapt this view with the recent Chomskyan multiple specifier approach.
} 
28) a. It is champagne that I like

b. What I like is champagne

(Lambrecht, 2001: p. 5)

Cleft constructions are one of the movement-like operations among others such as extraction, extraposition etc. However, these constructions do not involve only syntactic movements (Legate, 1998: p. 4; Matushansky, 2005: p. 161). Full phrases are assumed to be targets of such movement operations. Thus, we may follow the idea that only such phrases are used to form cleft constructions. Consider the contrast given below:

29) a. It is [cp that Desdemona was faithful] that Othello doubted

b. *It is [xp doubt that Desdemona was faithful] that Othello did.

What is seen above is that a full phrasal category CP is allowed to be constructed as a cleft whereas some parts of $v \mathrm{P}$ are not allowed to be extracted to be constructed as a cleft. If we apply the same strategy to what is assumed to be full phrases (i.e. prepositional verbs) in the context of verbal phrases, we will see that only such full phrases are allowed to be clefts:

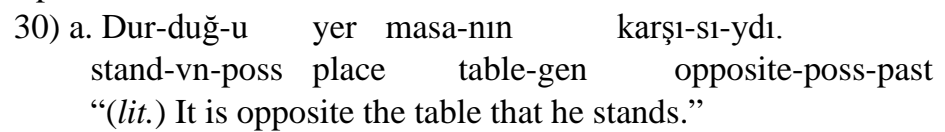

b. *Çıktığı (şey/yer/...) baba-sı-na karşı-ydı. stand something/place/... father-poss-dat against-past

“? What he stood against was his father"

The fact that we have to use a noun semantically denoting "place" is the implication of the fact that the predicate of (30a) is nothing but a postpositional phrase, since this postpositional phrase conceptualizes a spatial relation between the place and the one who stands. On the contrary, no noun denoting "place" can be used in (30b) as the relationship between the agent and the theme is not a spatial one.

Therefore, we may also claim that this distinction is proved by means of such a cleft-construction test. What is coming next is a weak but still semantically sound test.

\subsection{Synonymy}

This is a semantic test in that the sequence of $[\mathrm{P}+\mathrm{V}]$ is considered to form a phrasal verb whose meaning is determined by the integrity of its merged lexical items; thus, such verbal groups can be alternated by another synonymous lexical item. If the alternated version of the phrase still yields grammatical and acceptable outcomes, then this implies the phrasal-verbhood of the verbal group. Consider these pairs:
31) a. Antrenör
oyuncu-ya
arka
çık-tı
trainer player-dat back

"The trainer backed up the player"

b. Antrenör oyuncuyu destekledi.

"The trainer supported the player"

Although there is a slight difference in the meaning between the sentences, it is still possible to use the phrasal verb arka çı-synonymous with the simple verb destekle-. This semantic test failed to account for why such an alternation cannot be made among prepositional verbs, yet it is another empirical ground to differentiate between two types of verbs.

\section{Interim Conclusion}

What we have seen so far is that the tests of movement, sentence fragment, adverb placement, postposition alternation, cleft constructions and synonymy revealed the difference in the construction of the phrasal and prepositional verbs. As remembered, the former type has been assumed to be constructed out of a verb merged with a postposition (in Turkish), while the latter is a sequence of a PP merged with a verb which together forms a VP. Therefore, the empirical background we have discussed above justifies such a distinction between these two kinds of verbs in terms of structurally and semantically.

We now move on to discuss the theoretical implications of such a distinction in terms of the phasehood of the PPs. First, we will discuss the relevant literature, and then we will show that agreeing Ps differ from the bare Ps in that the former can constitute a phase, while the second cannot. 


\section{Theoretical Implications}

Drummond et al. (2010) argues that A'-movement operations that move elements to the left are able to strand prepositions, but the reverse is impossible:

32) a. John looked at [the man who lived next door] in the living room yesterday.

b. *John looked at $t_{1}$ in the living room yesterday [the man who lived next door $]_{1}$

They also argue that there is no explanation as to this directional asymmetry of P-stranding in the literature. Therefore, they suggest that this asymmetry can be captured under three common assumptions, one of which is directly related to the phasehood of PPs. This assumption clearly states that PP is a phase, and that the languages differ in whether or not intermediate movement to Spec, PP is possible.

Şener (2006) also argues in almost the same direction in that he states that in Turkish there are two kinds of Ps: the bare and agreeing. As for the asymmetry discussed by Drummond et al. (2010), he differentiate the former from the latter in that the bare Ps allows no stranding, while the agreeing Ps have escape hatches, meaning that they do allow such stranding operations. Consider this asymmetry taken from Şener (2006):

33) a. *Biz [Pelin-in arkadaş-1 $]_{\mathrm{i}} \quad$ dün $\left[\mathrm{pp} t_{\mathrm{i}}\right.$ için $]$ para topla-dı-k.

we Pelin-gen friend-poss yesterday for money collect-past-1pl

"Yesterday, we collected money for Pelin's friend."

b. Ben Pelin-in $n_{\mathrm{i}}$ dün $\quad\left[\mathrm{pp} t_{\mathrm{i}}\right.$ yan-1n-da] konuş-tu-m.

I Pelin-gen yesterday beside-3sg-loc speak-past-1sg

"I spoke (while I was) next to Pelin yesterday (Not while I was behind her)."

He explains this asymmetry referring to what is known as Antilocality Condition (Abels, 2003):

34) Antilocality Condition (ALC)

No phrase can be both the complement and the specifier to the same Head as the movement from comp to spec will be too local.

Şener (2006: p. 4) argues that Phase Impenetrability Condition (PIC) $)^{3}$ derives successive cyclicity effects, thus, the dilemma deriving the ALC is that movement to Spec of a phase is required by the PIC, though such a movement is banned not having a Last Resort flavor because any feature that can be checked in Spec position can already be checked in complement position.

The discussions above are deeply bound to the discussions we have presented with respect to the distinction between phrasal and prepositional verbs. In fact, they provide insights as to the phasehood of PPs in the sense of Drummond et al. (2010).

First, let us assume that phases carry two distinct areas. One of them is the spell-out domain which is sent to the interfaces after all the operations are completed phase-internally. The other one is the edge where there is the phase head and an escape hatch (i.e. multiple specifier positions) through which elements can be moved successive cyclically in order to be seen by the higher phases. Given this assumption, we may argue that as the prepositional verbs include agreeing-Ps and allow subextraction (see (13)), it can be stated that they are phases:

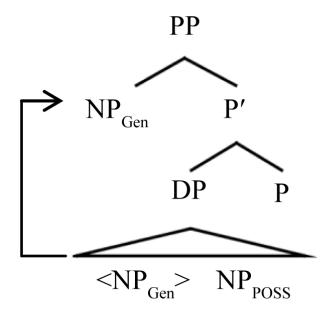

35)

(Adapted from Şener, 2006)

As can be seen, agreeing-Ps carry edge feature, which means that they have escape hatches through which $\mathrm{NP}_{\mathrm{Gen}}$ can escape through higher phases. The fact that this phase has escape hatches implies that such agreeingPs can constitute phases.

On the other hand, bare-Ps do not display the same properties with respect to the subextraction from their spell-out domain. Therefore, there are two possibilities of the structuring of bare PPs. One is simply merging P

\footnotetext{
${ }^{3}$ In phase $\alpha$ with head $\mathrm{H}$, the domain of $\mathrm{H}$ is not accessible to operations outside $\alpha$, only $\mathrm{H}$ and its edge are accessible to such operations (Chomsky, 2001).
} 
with an $\mathrm{N}$ head, while the second is to assume them as a phase and assigning them an edge:

However, if $b$ were the case, then (33a) would be licensed and there would be no ungrammaticality. Note that prepositional verbs in Turkish allow extraction, while phrasal verbs do not. This clearly shows that prepositional verbs in Turkish include agreeing-Ps; thus, a phase, while phrasal verbs are composed of a bare P merged with $\mathrm{V}$.

\section{Conclusion}

We aimed to explore the question as to whether there are phrasal verbs as opposed to prepositional verbs in Turkish. For this research question of the study, we employed eight different tests. Movement test suggested that only full phrases could undergo movement; therefore, it revealed the distinction between prepositional and phrasal verbs in that the prepositional verbs could undergo movement since they are truly full phrases. In a similar fashion, sentence fragment test suggested that the full phrases could be used as sentence fragments; therefore, only prepositional verbs could be used as sentence fragments as opposed to phrasal verbs. The adverb placement test offered us a way to distinguish between these two kinds of verbs. Following Cinque (1999), we inserted low adverbs between the PP and V in prepositional verbs. We employed the same strategy in what was assumed as phrasal verbs. The grammaticality of the former revealed that two structures differed in their construction. Another test, postposition alternation, also revealed the distinction between two verbal types in that in prepositional verbs we could insert different spatial postpositions while we could not apply the same strategy on phrasal verbs. Cleft construction test, in a similar way with movement and sentence fragment, suggested that only full phrases could be clefted; thus, the ungrammaticality when applied on phrasal verbs. The last test, synonymy, can also be counted as another piece of evidence with respect to the distinction in the construction of the two types of verb groups.

The fact that some types of prepositions, namely, agreeing Ps can be found in prepositional verbs in Turkish theoretically implies us that agreeing Ps has edge features which allow subextraction of an internal element within the phasal domain in a cyclic fashion; thus, they can be counted as a phase. On the other hand, as phrasal verbs are composed of a V merged with $\mathrm{P}$, no edge feature is assigned to that coplex; thus, this bare $\mathrm{P}$ cannot constitute a phase as remembered for the tests we have employed.

These findings are vague in that the phasal status of such phrases should be proved by independent evidences. For instance, if we follow Lee-Schoenfeld (2004: p. 147) and assume that an anaphor should be co-indexed with an antecedent in its accessible phase, then we should presuppose that anaphors must only be bound with antecedents which is contained within the same phase in the context of PPs. However, this is not the case for either agreeing Ps or bare Ps:

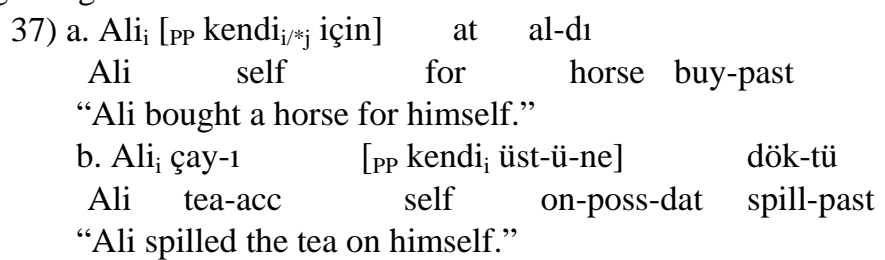

Although the full phrasal status and edge features of PPs suggest that they may be phases, other diagnostics such as binding reveals controversy as to the phasal status of such phrases. We leave this controversial issue to future research.

\section{References}

Abels, K. (2003). Successive Cyclicity, Anti-Locality, and Adposition Stranding. Doctoral Dissertation, University of Connecticut, Storrs. 
Chomsky, N. (2000). Minimalist Inquiries: The Framework. In R. Martin, D. Michaels, \& J. U. (Eds.), Ícinde, Step by Step (pp. 89-156). Cambridge, MA: MIT Press.

Chomsky, N. (2001). Derivation by Phase. In M. Kenstowicz (Ed.), İcinde, Ken Hale: A Life in Language (pp. 1-52). Cambridge, MA: MIT Press.

Chomsky, N. (2004). Beyond Explanatory Adequacy. In A. B. (Ed.), Ícinde, Structures and Beyond. Oxford: Oxford University Press.

Chomsky, N. (2008). On Phases. In R. Freidin, C. P. Otero, \& M. L. Zubizarreta (Eds.), Foundational Issues in Linguistics Theory (pp. 133-166). Cambridge, MA: MIT Press. http://dx.doi.org/10.7551/mitpress/9780262062787.003.0007

Cinque, G. (1999). Adverbs and Functional Heads-A Crosslinguistic Perspective. Oxford: Oxford University Press.

Drummond, A., Hornstein, N., \& Lasnik, H. (2010). A Puzzle about P-Stranding. Linguistic Inquiry, 41, 689-693.

Göksel, A., \& Kerslake, C. (2005). Turkish: A Comprehensive Grammar. London \& New York: Routledge. http://dx.doi.org/10.4324/9780203340769

Kornfilt, J. (1997). Turkish. Blackwell: Routledge

Lambrecht, K. (2001). A Framework for the Analysis of Cleft Constructions. Linguistics, 39, 463-516. http://dx.doi.org/10.1515/ling.2001.021

Lee-Schoenfeld, V. (2004). Binding by Phase: (Non-)Complementarity in German. Journal of Germanic Linguistics, 16, 111-173.

Legate, A. J. (1998). Verb Phrase Types and the Notion of a Phase. Cambridge, MA: MIT Press.

Lewis, G. L. (1975). Turkish Grammar (2nd ed.). Oxford: Oxford University Press.

Matushansky, O. (2005). Going through a Phase. In MIT Working Papers in Linguistics 49: Perspectives on Phases (pp. 157-181). Cambridge, MA: Department of Linguistics, MITWPL.

Radford, A. (1988). Transformational Grammar. Cambridge, MA: University Press. http://dx.doi.org/10.1017/cbo9780511840425

Şener, S. (2006). Antilocality and P-Stranding. Anti-Locality Çalıştayı. Nisan 22, 2006 Harvard University.

Turan, Ü. D. (2002). Cleft Sentence. In G. König, N. Büyükkantarcığlu, \& F. Karahan (Eds.), Proceedings of the 16th National Linguistics Conference (pp. 59-68). Ankara: Hacettepe University Press. 